\title{
Pro-Inflammatory Cytokines (TNF- $\alpha$ and IL-1) in Nigerian Women with Breast Cancer
}

\author{
Chukwurah Ejike Felix ${ }^{1 *}$, Iyare Festus Ehigiator ${ }^{2}$, Chukwurah Felix Chinedum ${ }^{3,4^{*}}$ \\ ${ }^{1}$ Department of Haematology \& Immunology, Faculty of Medicine, Ebonyi State University, Abakaliki, Nigeria \\ ${ }^{2}$ Department of Morbid Anatomy, Faculty of Medicine, Ebonyi State University, Abakaliki, Nigeria \\ ${ }^{3}$ Shenyang Medical College, Shenyang, China \\ ${ }^{4}$ Department of Surgery, Enugu State University Teaching Hospital, Enugu, Nigeria \\ Email: medichemlabenugu@yahoo.com, festus_iyare@yahoo.com, ${ }^{\star}$ felixcz042@gmail.com
}

How to cite this paper: Felix, C.E., Ehigiator, I.F. and Chinedum, C.F. (2018) Pro-Inflammatory Cytokines (TNF- $\alpha$ and IL-1) in Nigerian Women with Breast Cancer. Open Journal of Immunology, 8, 13-28.

https://doi.org/10.4236/oji.2018.82002

Received: May 17, 2018

Accepted: June 17, 2018

Published: June 20, 2018

Copyright $\odot 2018$ by authors and Scientific Research Publishing Inc. This work is licensed under the Creative Commons Attribution International License (CC BY 4.0).

http://creativecommons.org/licenses/by/4.0/

\section{Open Access}

\begin{abstract}
Background: Breast cancer remains an important medical challenge, despite sustained global efforts at its prevention and control. Various immunological factors are expressed in the serum during breast tumourigenesis, and can be of value in the surveillance of the disease. These serum bio-markers include pro-inflammatory cytokines since breast cancer is associated with chronic inflammation. In our locality with different racial/ethnic variations from Caucasian as well as environmental factors, there is scanty information on the value of these serum factors in screening and surveillance of breast cancer-hence the need for this study. Methodology: A total of 68 females (mean age $=48.7 \pm$ 8.7 yrs) with clinically and pathologically confirmed breast cancer were recruited by self selection; representing breast cancer patients group. Due to small sample size they were further grouped into advanced stage breast cancer cases $(\mathrm{N}=40)$ and early stage breast cancer cases $(\mathrm{N}=28)$. Controls consisted of two groups: A-Patient control group $(\mathrm{N}=21)$ comprised females with benign breast tumour ( 15 cases with fibroadenoma and 6 cases with fibrocystic disease) and group $\mathrm{B}$-apparently healthy age/sex matched control group ( $\mathrm{N}$ = 21). Pre-treatment samples were collected after which all patients underwent standard treatment modalities (neoadjuvant or adjuvant chemotherapy, radiotherapy, chemoradiation, and/or surgery; depending on the stage of presentation and thereafter post treatment samples were collected after 3 and 6 months respectively. Serum from the patients and controls were assayed immunoenzymatically for TNF- $\alpha$ and IL-1. Results: The results showed that at 6 months post-treatment stage, the mean values of IL-1 differed significantly $(\mathrm{P}>0.05)$ when advanced stage breast cancer were compared with early stage and apparently healthy control groups respectively. Likewise at 6 months post-treatment stage, the TNF- $\alpha$ mean values differed significantly $(\mathrm{P}>0.05)$
\end{abstract}


between advanced stage breast cancer and apparently healthy control. No significant differences in mean values were recorded across disease and treatment groups in both IL-1 and TNF- $\alpha$ at pre-treatment and 3 months post-treatment stages. Majority of the breast cancer patients studied were married (91\%) and had children, of low income, never smoke cigarette, diagnosed at age above 46 years and presented at advanced stages of the disease. Results also showed that $78 \%$ of the cases did not have any history of cancer in their families. Also, $63 \%$ of the cases had body mass index values suggestive of obesity $\left(>30 \mathrm{~kg} / \mathrm{m}^{2}\right)$. Conclusion: Results suggest that the use of serum levels of TNF- $\alpha$ and IL-1 in the diagnosis of breast cancer in our racial/ethnic environment is of limited clinical value. However it could be useful in disease surveillance in metastasis and relapse. Based on our findings, it could also be concluded that cigarette smoking and social sophistication are not among the risk factors to cancer in this part of the world, contrary to the situation in the advanced parts of the world.

\section{Keywords}

Breast Tumour, TNF- $\alpha$, IL-1, Diseases Stages

\section{Introduction}

The incidence of breast cancer is increasing worldwide [1] [2] [3] even among countries that used to have low prevalence with some genetic variables as a result of environmental and other factors. It is the most frequently diagnosed cancer in women and the leading cause of cancer related death [2] [3]. Thus, there is the need to develop immunological based techniques with diagnostic and/or prognostic potentials.

African countries present with low prevalence, more aggressive, increased mortality, earlier age at presentation (35 - 45 years) and different pattern of gene expression [4] [5] [6]. Various risk factors accounting for difference in prevalence rates have been identified and include genetic and epigenetic factors largely due to breast cancer gene type 1 (BRCA 1 ) and breast cancer gene type 2 (BRCA 2) mutations [7] [8], history of breast cancer, ethnicity, reproduction factors [9] [10] [11] and menstrual history. Breast cancer is a heterogeneous disease with a large number of prognostic variables.

The tumour microenvironment is an important aspect of cancer biology that contributes to tumour initiation, tumour progression and responses to therapy. The composition and characteristics of the tumour microenvironment vary widely and are important in determining the anti-tumour immune response [12]. Most cancers arise in association with chronic inflammation and contain inflammatory infiltrates [13]. Immune cells have broad impact on tumour initiation, growth, and progression and many of these effects are mediated by some cytokines. Among these cytokines, the pro-tumourigenic function of tumour 
necrosis factors (TNF- $\alpha$ ), interleukin-6 (IL-6), IL-1, IL-12 are well established [14] [15] [16] [17] [18]. Studying the immunological mechanisms of some pro-inflammatory cytokines across racial/ethnic divide therefore, is of immense clinical importance.

Tumour necrosis factor (TNF- $\alpha$ ) mediates a broad range of biological activities and encompasses beneficial effects for the host in inflammation and in protective immune responses against a variety of infectious pathogens [19]. Pro-inflammatory cytokine TNF- $\alpha$ is required for de novo carcinogenesis and is important to early stages of tumour promotion [20], acts as a mediator for IL-1 and IL- 8 production and induces NF-B signaling pathway activation in stem-like phenotype [21]. In response to inflammation and infection, TNF- $\alpha$ elicits its pro-inflammatory signals by initially binding to receptors, TNFR1 (p55) and TNFR2 (p75) on the cell surface [22] via three distinct signaling pathways leading to the activation of caspases and the activation of AP-1 and $\mathrm{NFkB}$ transcription factors which lead to a range of cellular responses, including cell death, survival, differentiation, proliferation and migration. The tumour-promoting functions of TNF- $\alpha$ is associated to its ability to induce proangiogenic functions, to promote the expression of matrix metalloproteinases (MMP) and endothelial adhesion molecules, and to cause DNA damage via reactive oxygen, the overall effect of which is promotion of tumor-related processes [23].

Interleukin 1 (IL-1); another inflammatory cytokine produced by activated macrophages with effects similar to that of TNF- $\alpha$ and also helps to activate $\mathrm{T}$ cells [22] [24]. There are two forms of this prototypic pro-inflammatory cytokine; IL- $1 \alpha$ and IL-1 $\beta$ and in most studies [25] [26]; their biological activities are indistinguishable and play an important role in immune regulation and inflammatory processes by inducing expression of many effector proteins, e.g. cytokines/chemokines, nitric oxide synthetase and matrix metalloproteinases (MMPs) [27]. IL-1 is involved in breast cancer progression and it is a potential inducer of IL-8 production by breast cancer cells in vitro [21]. Excessive and/or dysregulated activity of these mediators is associated with tissue destruction and therefore the synthesis, secretion and biological activity of IL-1 cytokines have been identified as therapeutic targets for common inflammatory disorders such as rheumatoid arthritis (RA) and periodontitis.

The outcome of breast cancer is usually determined by multiple factors. Serum tumor necrosis factor alpha (TNF- $\alpha$ ) concentration has been found to be increased in the circulation of patients with malignancy. Preoperative evaluation of serum TNF- $\alpha$ concentration has been found to be a valuable parameter for reflecting the severity of staging for invasive breast cancer [28] and correlate with response to neoadjuvant chemotherapy in locally advanced breast cancer [29]. Discrete roles of IL-6, IL-1 and TNF- $\alpha$ in tumour promotion and cell transformation have been demonstrated [15] [30] and found to be of good clinical importance. In breast cancer, the IL-1 levels is significantly higher in invasive car- 
cinoma than in ductal carcinoma in situ or in benign lesions, implying that elevated levels of IL-1 are directly correlated with a more advanced disease [31]. Most of these studies were done on patients of different racial/ethnic backgrounds.

Race/ethnicity has been associated with expression of proteins and especially inflammatory cytokines in various diseases [32] [33] [34] [35] [36]. Differences by race in incidence for diseases associated with inflammation suggest that there may be underlying racial differences in inflammatory pathway genes [35]. The incidence of several types of cancer associated with inflammation and/or chronic infection is also elevated in African Americans relative to Caucasians [37] [38]. It is therefore necessary to examine some of these pro-inflammatory cytokines as they affect women from this environment.

\section{Materials and Methods}

\subsection{Subjects and Sampling}

This is a prospective longitudinal study conducted between February 2015 and June; 2017 on female patients referred to the Oncology Units of Departments of Surgery of University of Nigeria Teaching Hospital, Enugu and Federal Teaching Hospital, Abakaliki (both in Eastern-Nigeria). Diagnosis and staging were clinically and pathologically confirmed.

Sixty eight 68 female breast cancer patients with age range from 30 to 70 years were eligible and recruited for this study; representing breast cancer patients group. Due to small sample size the patients were further divided into early stage breast cancer (stages 1 and $2 ; \mathrm{N}=28$ ) and advanced stage breast cancer (stages 3 and 4; $\mathrm{N}=40$ ) based on Tumour, Node, Metastasis (TNT) classification. Controls consisted of two groups: A-Patient control group: Twenty one (21) females with benign breast tumour (15 cases with fibroadenoma and 6 cases with fibrocystic disease) were involved in this study as benign breast tumour (BBT) patient control group B-apparently age/sex matched healthy control (AHMC) group: A total of 21 healthy females' volunteers who have no history or clinical evidence of any breast lesions drawn from the Hospital and University Communities were selected as a healthy control group.

Sampling was by self-selection following the approval of the study protocol by the respective Hospitals Ethical Committee, informed written consent obtained from the individuals and exclusion criteria applied. Breast tumour patients who received any therapy prior to diagnosis (surgery/radiotherapy/chemotherapy), previous history of malignancy and history of any other medical illness, which would otherwise limit the survival of the patient in the absence of malignancy, were excluded. All patients underwent standard treatment modalities (neoadjuvant or adjuvant chemotherapy, radiotherapy, chemoradiation, and/or surgery; depending on the stage of presentation. In breast cancer (BC) patients and benign breast tumour (BBT) patients control groups, blood samples were collected before any form of treatment and two more samples at 3 and 6 months interval. 
In apparently healthy sex/age-matched control, one blood sample was taken from each participant. The samples were allowed to clot, centrifuged at 5000 $\mathrm{rpm}$ for 5 minutes, serum separated and stored at $-20^{\circ} \mathrm{C}$ until analyzed.

\subsection{Assay Methods}

Abcam's TNF- $\alpha$ in vitro Simple StepTM ELISA method were adopted for TNF- $\alpha$ (kit sourced from abcamR, UK, Cat \#ab181421) and IL-1a (kit sourced from abcamR, UK, Cat \#ab178008) estimations. The simple Step ELISA employs a labeled capture and detector antibody which immunocaptures the sample analyte in solution. This entire complex (capture antibody /detector antibody) is in turn immobilized in the well by immunoaffinity via the anti-tag antibody. Sample or standard are added to wells, followed by the antibody mix. After incubation, the wells are washed to remove unbound material; the TMB substrate is then added. The reaction is stopped by addition of stop Solution which stops the colour development and completes any colour change from blue to yellow. Signal is generated proportionally to the amount of bound analyte and the intensity is measured at $450 \mathrm{~nm}$.

A standard curve was constructed for each method using the respective standard and use for the determination of unknown respective serum sample concentrations.

\subsection{Statistical Analysis}

Data were analyzed using statistical package for Social Sciences (SPSS) software. Statistical significance was set at $\mathrm{p}<0.05$. Dunn's multiple comparison tests and Kruskall-Wallis analysis of variance were applied for measuring the differences between disease and treatment groups. GraphPad prism version 6.0 (by GraphPad, USA) was used for the graphs.

\section{Results}

Majority of the breast cancer patients studied were married (91\%) and had children, of low income, never smoke cigarette, diagnosed at age above 46 years and presented at advanced stages of the disease. Results also showed that $78 \%$ of the cases did not have any history of cancer in their families. Also, $63 \%$ of the cases had body mass index values suggestive of obesity $\left(>30 \mathrm{~kg} / \mathrm{m}^{2}\right)$. Table 1 shows some demographic parameters of the breast cancer patients studied.

The mean values and statistical comparison of TNF- $\alpha$ and IL-1 in disease groups (breast cancer cases and benign breast tumour) were presented in Table 2 \& Table 3 respectively. The results showed that at 6 months post-treatment stage, the mean values of IL-1 differed significantly $(\mathrm{P}>0.05)$ when advanced stage breast cancer were compared with early stage and apparently healthy control groups respectively. Likewise at 6 months post-treatment stage, the TNF- $\alpha$ mean values differed significantly $(\mathrm{P}>0.05)$ between advanced stage breast cancer and apparently healthy control. No significant differences in mean values 
Table 1. Some demographic parameters of breast cancer patients.

\begin{tabular}{ccccc}
\hline Variable & Number (n) & Minimum & Median & Maximum \\
\hline Age at diagnosis (years) & 68 & 31 & 51 & 69 \\
Age at menarche (years) & 65 & 10 & 13 & 16 \\
Age of menopause (years) & 42 & 41 & 49 & 55 \\
Body mass index (kg/m²) & 68 & 19.2 & 30.8 & 43.5 \\
\hline
\end{tabular}

were recorded across disease and treatment groups in both IL- 1 and TNF- $\alpha$ at pre-treatment and 3 months post-treatment stages.

No statistical significant difference in TNF- $\alpha$ and IL-1was observed when the breast cancer groups were condensed. Similar results were recorded instead.

\section{Discussion}

Despite the improvement in health facilities; majority of the patients in this study were of low income level and presented at advanced stages of the disease when little or no benefit can be derived from any form of therapy. Out of the 68 breast cancer cases studied, 28 patients presented at early stage (stages 1 and 2), while 40 patients presented at advanced stage of the disease (stages 3 and 4). This could be attributed to poverty, lack of free screening centers and ignorance; giving room for incorporeal interpretation for such health problems. This is indeed worrisome and a major challenge. There is the need therefore for development of measures for early detection of the disease through mass enlightenment and free breast cancer screening at all levels (targeting women organizations and schools) and encouraging regular self-breast examination. The silent nature of breast cancer at onset makes it difficult to be detected early, demanding improved, sensitive and affordable screening procedures. Unfortunately early detection through mammography, routine and self-breast examinations which are so effective in educated communities are seldom applicable in poorly educated ones in whom the carcinomas commonly present late [39]; intensive education and training of women groups by the government and non-governmental organization should be encouraged and extended to rural communities.

Biological markers are widely recognized as important tools in the evaluation and management of patients with cancer. An especially wide array of body fluid markers have been investigated for clinical utility in diagnosing, staging or managing patients with cancer [40] [41] [42]. Clinical uses of biomarkers include screening and diagnosis of breast cancer; staging and monitoring response to therapy.

Most cancers arise with the association of chronic inflammation and contain inflammatory infiltrates [13]. Immune cell have broad impact on tumour initiation, growth, and progression and many of these effects are mediated by profile cytokines. Among these cytokines, the pro-tumourigenic function of tumour necrosis factors (TNF- $\alpha$ ), IL-6, IL-1, IL-12 are well established [15] [16] [17].

The cytokines produced by these cells have been posited as key factors in 
Table 2. Comparison of TNF- $\alpha$ according to disease and of treatment groups.

\begin{tabular}{|c|c|c|c|c|c|c|}
\hline Treatment group & Disease stages & $\begin{array}{c}\text { Mean } \\
(\mathrm{Pg} / \mathrm{ml})\end{array}$ & Std. Dev & $\mathrm{N}$ & $\begin{array}{c}\text { Mean } \\
\text { diff } \pm \text { S.E }\end{array}$ & p-value \\
\hline \multirow[t]{12}{*}{ Pretreatment } & ESBC & 102.24 & 34.09 & 28 & $9.96 \pm 7.29$ & 0.175 \\
\hline & ASBC & 92.29 & 24.03 & 40 & & \\
\hline & ESBC & 102.24 & 34.09 & 28 & $16.76 \pm 9.27$ & 0.074 \\
\hline & AHMC & 85.49 & 22.32 & 21 & & \\
\hline & ESBC & 102.24 & 34.09 & 28 & $5.06 \pm 8.32$ & 0.545 \\
\hline & $\mathrm{BBT}$ & 97.19 & 36.12 & 21 & & \\
\hline & ASBC & 92.29 & 24.03 & 40 & $6.80 \pm 8.75$ & 0.439 \\
\hline & AHMC & 85.49 & 22.32 & 21 & & \\
\hline & ASBC & 92.29 & 24.03 & 40 & $4.90 \pm 7.74$ & 0.528 \\
\hline & $\mathrm{BBT}$ & 97.19 & 36.12 & 21 & & \\
\hline & BBT & 97.19 & 36.12 & 21 & $11.70 \pm 9.63$ & 0.227 \\
\hline & AHMC & 85.49 & 22.32 & 21 & & \\
\hline \multirow{12}{*}{$\begin{array}{c}3 \text { months } \\
\text { post-treatment }\end{array}$} & ESBC & 95.64 & 38.89 & 28 & $96.24 \pm 56.14$ & 0.090 \\
\hline & ASBC & 191.88 & 366.68 & 38 & & \\
\hline & ESBC & 95.64 & 38.89 & 28 & $10.15 \pm 71.40$ & 0.887 \\
\hline & AHMC & 85.49 & 22.32 & 21 & & \\
\hline & ESBC & 95.64 & 38.89 & 28 & $17.19 \pm 64.91$ & 0.792 \\
\hline & $\mathrm{BBT}$ & 78.45 & 11.13 & 20 & & \\
\hline & ASBC & 191.88 & 366.68 & 38 & $106.39 \pm 67.39$ & 0.118 \\
\hline & AHMC & 85.49 & 22.32 & 21 & & \\
\hline & ASBC & 191.88 & 366.68 & 38 & $113.43 \pm 60.47$ & 0.064 \\
\hline & $\mathrm{BBT}$ & 78.45 & 11.13 & 20 & & \\
\hline & BBT & 78.45 & 11.13 & 20 & $7.04 \pm 74.86$ & 0.925 \\
\hline & AHMC & 85.49 & 22.32 & 21 & & \\
\hline \multirow[t]{12}{*}{$\begin{array}{c}6 \text { months } \\
\text { post-treatment }\end{array}$} & ESBC & 93.78 & 22.12 & 26 & $17.03 \pm 10.14$ & 0.097 \\
\hline & ASBC & 102.70 & 46.72 & 31 & & \\
\hline & ESBC & 93.78 & 22.12 & 26 & $8.30 \pm 12.52$ & 0.051 \\
\hline & AHMC & 85.49 & 22.32 & 21 & & \\
\hline & ESBC & 93.78 & 22.12 & 26 & & \\
\hline & $\mathrm{BBT}$ & - & - & - & & \\
\hline & ASBC & 102.70 & 46.72 & 31 & $25.33 \pm 11.83$ & 0.036 \\
\hline & AHMC & 85.49 & 22.32 & 21 & & \\
\hline & ASBC & 102.70 & 46.72 & 31 & & \\
\hline & BBT & - & - & - & & \\
\hline & BBT & - & - & - & & \\
\hline & AHMC & 85.49 & 22.32 & 21 & & \\
\hline
\end{tabular}

Key: ESBC-Early stage breast cancer. ASBC-Advanced stage breast cancer. AHMC-Apparently healthy control. BBT-Benign breast tumour. 
Table 3. Comparison of the IL-1 across to disease and treatment groups.

\begin{tabular}{|c|c|c|c|c|c|c|}
\hline Treatment groups & $\begin{array}{l}\text { Disease } \\
\text { stages }\end{array}$ & $\begin{array}{l}\text { Mean } \\
(\mathrm{Pg} / \mathrm{ml})\end{array}$ & Std. Dev & $\mathrm{N}$ & Mean diff \pm S.E & p-value \\
\hline \multirow[t]{17}{*}{ Pretreatment } & ESBC & 56.31 & 29.57 & 28 & $17.17 \pm 14.22$ & 0.230 \\
\hline & ASBC & 73.40 & 76.36 & 40 & & \\
\hline & ESBC & 56.31 & 29.57 & 28 & $10.40 \pm 18.08$ & 0.566 \\
\hline & AHMC & 45.91 & 25.74 & 21 & & \\
\hline & ESBC & 56.31 & 29.57 & 28 & $24.13 \pm 16.24$ & 0.140 \\
\hline & BBT & 80.44 & 61.03 & 21 & & \\
\hline & ASBC & 73.40 & 76.36 & 40 & $27.57 \pm 17.07$ & 0.109 \\
\hline & AHMC & 45.91 & 25.74 & 21 & & \\
\hline & ASBC & 73.40 & 76.36 & 40 & $6.96 \pm 15.10$ & 0.646 \\
\hline & BBT & 80.44 & 61.03 & 21 & & \\
\hline & BBT & 80.44 & 61.03 & 21 & $34.54 \pm 18.78$ & 0.069 \\
\hline & AHMC & 45.91 & 25.74 & 21 & & \\
\hline & ESBC & 77.48 & 61.32 & 28 & $1.94 \pm 18.82$ & 0.918 \\
\hline & ASBC & 75.54 & 110.88 & 38 & & \\
\hline & ESBC & 77.48 & 61.32 & 28 & $31.57 \pm 23.93$ & 0.190 \\
\hline & AHMC & 45.91 & 25.74 & 21 & & \\
\hline & ESBC & 77.48 & 61.32 & 28 & $33.64 \pm 21.76$ & 0.125 \\
\hline \multirow[t]{12}{*}{3 months Post-treatment } & BBT & 43.83 & 13.60 & 20 & & \\
\hline & ASBC & 75.54 & 110.88 & 38 & $29.63 \pm 22.59$ & 0.193 \\
\hline & AHMC & 45.91 & 25.74 & 21 & & \\
\hline & ASBC & 75.54 & 110.88 & 38 & $31.70 \pm 20.27$ & 0.121 \\
\hline & BBT & 43.83 & 13.60 & 20 & & \\
\hline & BBT & 43.83 & 13.60 & 20 & $2.07 \pm 25.09$ & 0.934 \\
\hline & AHMC & 45.91 & 25.74 & 21 & & \\
\hline & ESBC & 59.00 & 39.77 & 26 & $33.37 \pm 14.37$ & 0.023 \\
\hline & ASBC & 95.58 & 72.77 & 31 & & \\
\hline & ESBC & 59.00 & 39.77 & 26 & $13.09 \pm 17.73$ & 0.463 \\
\hline & AHMC & 45.91 & 25.74 & 21 & & \\
\hline & ESBC & 59.00 & 39.77 & 26 & & \\
\hline 6 months & BBT & - & - & - & & \\
\hline \multirow[t]{6}{*}{ Post-treatment } & ASBC & 95.58 & 72.77 & 31 & $46.47 \pm 16.77$ & 0.007 \\
\hline & AHMC & 45.91 & 25.74 & 21 & & \\
\hline & ASBC & 95.58 & 72.77 & 31 & & \\
\hline & BBT & - & - & - & & \\
\hline & BBT & - & - & - & & \\
\hline & AHMC & 45.91 & 25.74 & 21 & & \\
\hline
\end{tabular}

Key: ESBC-Early stage breast cancer. ASBC-Advanced stage breast cancer. AHMC-Apparently healthy control. BBT-Benign breast tumour. 
modulating immune response either against or in favor of tumourigenesis in the microenvironment. Several pro-inflammatory gene products have been identified that mediate a critical role in suppression of apoptosis, proliferation, angiogenesis, invasion, and metastasis [18]. Among these gene products are TNF and members of its super family, IL- $1 \alpha$, IL- $1 \beta$, IL-6, IL-8, and IL- 18 .

Studies in racial/ethnic variations of TNF- $\alpha$ in different disease states have been documented with varied opinions [30] [43]. The role of TNF and IL-6 as master regulators of tumour-associated inflammation and tumourigenesis makes them attractive targets for adjuvant treatment in cancer [13].

Immunohistochemistry reports [44] [45] [46] on cytokines and cytokine receptors however revealed among others; that the inflammatory chemokines CCL2 (MCP-1) and CCL5 (RANTES) and the inflammatory cytokines TNF- $\alpha$ and IL- $1 \beta$ were shown to contribute to breast cancer development and metastasis. Soria et al. (2011) [46] observed that 1) Tumors of the invasive ductal carcinoma (IDC)-with-relapse group had significantly higher persistence of TNF- $\alpha$ and IL- $1 \beta$ compared to tumors of ductal carcinoma in-situ (DCIS) or IDC-no-relapse; 2) Continuous stimulation of the tumor cells by TNF- $\alpha$ (and to some extent IL-1 $\beta$ ) has led to epithelial-to-mesenchymal transition (EMT) in the tumor cells. Similar study supported this finding and further affirmed that TNF- $\alpha$ exerts apoptosis in an intracellular transduction pathway that involves the kinase proteins TRAF-2 (integration point of apoptotic and survival signals), ASK1 (pro-apoptotic protein), MEK-4 (p38 activator and metastasis suppressor gene), JNK (stress mitogen activated protein kinase) and the transcription factor AP-1 [47]. These findings suggested that the coordinated expression of CCL2 and CCL5 and TNF- $\alpha$ and IL- $1 \beta$ may be important for disease course, and that TNF- $\alpha$ and IL- $1 \beta$ may promote disease relapse.

The work of Saganuma [15] et al. (2002) gave insight on the role of pro-inflammatory cytokines in de novo carcinogenesis. This finding was collaborated by other studies [20] [26] with clear evidence in experimental animals' that TNF- $\alpha$ is important to early stages of tumour promotion. Strategies that neutralize TNF- $\alpha$ production or using experimental animals' deficient in TNF- $\alpha$ have been found useful in cancer treatment and prevention [16] [17]. The role of TNF- $\alpha$, IL- 1 and IL- 6 as master regulators of tumour-associated inflammation and tumourigenesis makes them attractive targets for adjuvant treatment in cancer. These findings provide further evidence for pro-cancer action of TNF- $\alpha$ and other profile cytokine antagonists in cancer prevention and treatment.

In this study, there were no significant variations in mean TNF- $\alpha$ values across disease and treatment groups in the pre-treatment and 3 months pos-treatment stages. However at 6 months post-treatment stage, the advanced stage breast cancer mean values deferred significantly with that of apparently healthy control. Higher persistence of TNF- $\alpha$ had been reported previously in metastatic breast cancer [46]. It is possible that normal plasma level and not necessarily increased level is required for initiation and promotion of tumouri- 
genesis in the black Negroid race like ours, since there are evidences of racial and ethnic variations in the expression of these signaling proteins. Absence of TNF using deficient TNF- $\alpha$ (TNF-/-) mice or blockade with neutralizing antibodyhave been associated to resistance to the development of benign and malignant tumours [16] [20]. Secondly, the insignificant association of serum TNF- $\alpha$ recorded in this work may possibly be due to abundance of TNF- $\alpha$ receptors in most tissues leading to binding of free TNF onto the tissues. Evidence of abundance of inflammatory cell infiltrates especially macrophages (M1 macrophages) and neutrophils has been established in tumour microenvironment and some of these cells are quite endowed with TNF- $\alpha$ receptors and also elaborate TNF- $\alpha$ that function in an autocrine fashion. It has been established that the endogenous IL-12 modulates the tumour promoter stimulation of inflammatory responses and may be another possible reason for insignificant TNF- $\alpha$ result in the present work. The development of chemical-induced (DMBA/TPA) skin tumours has been found to diminish in IL-12 knockout mice than in their wild counterparts. One may postulate therefore, that IL-12 can possibly influence the expression of the pro-inflammatory cytokines. This work did not however, measure IL-12 to support the hypothesis. There is need therefore for further studies on the role of IL-12 in tumourigenesis and the possible association with other pro-inflammatory cytokine. Interleukin (IL-12) may be a possible tumour marker and not TNF- $\alpha$, IL- 1 and or IL- 6 in clinical diagnosis and prognosis in breast cancer and cancers in general.

Interleukin 1 (IL-1); another pro-inflammatory cytokine strongly expressed by monocytes, tissue macrophages, dendritic cells, B lymphocytes and NK cells refers to two proteins encoded by two different genes (IL-1a and IL-1b), both of which share the same cell surface receptors. The IL-1 signaling via its receptors generates local and systemic responses to injury and infection, thereby inducing fever, pain, sensitivity, vasodilatation, hypotension and slow wave sleep; essential processes towards the re-establishment of tissue homeostasis. Prolonged and inappropriate IL-1 induction is shown to be associated with sepsis, rheumatoid arthritis, inflammatory bowel disease, acute myelogenous leukemia, insulin-dependent diabetes mellitus and atherosclerosis [30] [43] in different racial/ethnic groups.

The role of interleukin-1 (IL-1) as determining factor in the immune and inflammatory responses to tumors cells [21] [45] and the ability of IL-1 to induce IL-8 expression in-vitro using human breast cancer (HBC) cell lines [47] has been demonsrtrated. The IL-1 cytokines are present in HBC tissue and homogenates; likewise IL-1 receptors (IL-1Rs) and IL-8 and correlate with prognostic indicators in HBC tumor microenvironment. The activation of the IL-1/IL-1R cytokine family via autocrine and/or paracrine mechanisms leads to a cascade of secondary pro-tumorigenic cytokines, induce the expression of numerous pro-tumorigenic activities such as the expression of IL-8, and subsequently contribute to angiogenesis, tumor proliferation and tumor invasion. A highly sig- 
nificant association exists between the (+3954) T allele of IL1-B gene and the aggressive phenotype of breast carcinoma as defined by the high histological grade, axillary lymph node metastasis and large tumor size [45].

In the present study the serum level of IL-1 was measured in malignant and benign breast diseases and at intervals after treatment to assess the clinical utility as a tumour marker. No significant difference was observed across the disease and treatment groups in pre-treatment and 3 months post-treatment. However at 6 months pre-treatment stage, the advanced breast cancer IL-1values differed significantly when compared with early stage and apparently healthy control. Higher persisted of IL-1 had been reported in metastatic breast cancer [46]. Previous studies also demonstrate that tumor-associated IL- $1 \alpha+$, IL- $1 \beta$ are present in the tumor microenvironment and may play a pivotal role in regulating breast tumor growth and metastasis. The expression of interleukin cytokines (IL)- $1 \alpha$, IL-1 $\beta$, and IL-1 receptor antagonist (IL-1ra) in human breast cancer (HBC) tissue has been demonstrated [48]. The absence of significant difference in cytokine level across disease groups and stages may probably be due to abundance of IL-1 receptors in this racial/ethnic group.

The study of Soria [46] et al. (2011) also emphasizes the importance of TNF- $\alpha$ and IL- $1 \beta$ in promoting disease metastasis and recurrence, gaining support by their high prevalence in patients in whom disease has relapsed. The possibility exists that different inflammatory mediators act in complementary manners at the tumor microenvironment to support processes of tumor growth and progression. One of such inflammatory mediators is the mannan-binding lectin (MBL) pathway of complement activation which is important in host defense against pathogens and possibly against cancer [49]. Mannan-binding lectin (MBL) plays a major role in innate immunity due to its ability to opsonize pathogens, to enhance their phagocytosis, and to activate the complement cascade via the lectin pathway. This inflammatory mediator has been shown to influence the inflammatory response to the initial injury in critical illnesses [50], decrease tumor necrosis factor release and other pro-inflammatory cytokines [49] and stimulate the production of anti-inflammatory cytokines such as interleukin-10 [50]. The MBL modulation of TNF is dose dependent; at low doses of MBL, increasing MBL concentration increases production of pro-inflammatory cytokines. But at higher concentrations, increasing MBL suppresses these inflammatory cytokines (ibid). It is possible that in critically ill patients with the low or defective MBL-producing genotypes, circulating MBL may not be sufficiently high or effective enough to switch from enhancement to suppression of the pro-inflammatory cytokine response.

The discrepancies between this study and the previous studies may lie in the fact that all our patients were of Negroid black race with different MBL polymorphism, in contrast to racial/ethnic different Caucasians. Though there is no known study on the MBL polymorphism in our environment; the polymorphism in MBL and MASP-2 gene is suggested to affect the serum concentration of MBL 
and MASP-2 [51]. Unfortunately, the functional significance of the $M B L$ polymorphisms and the inflammatory response of these patients could not be studied in this work. Additional studies are clearly needed to investigate the possible mechanisms by which $M B L-2$ genotypes may be important in tumourigenesis and tumour progression. It is most probable that the defective $M B L 2 \mathrm{O}$ allele is one of several other predisposing risk factors, likely to act in synergy with other factors, both genetic and environmental, in the development of the disease. The mechanisms responsible for MBL interactions with inflammatory pathways are still largely un-known but we do know that MBL receptors exist on phagocytic cells and may affect functions such as phagocytosis and cytokine production Further studies are recommend aimed at immunochemical characterizations of the cytokine genotypes and receptor status as well as interactions with other immunological molecules. Possible association in diagnostic and prognostic utility may be deduced.

Breast cancer remains intractable and common among women, possible potentials of these biomarkers in early diagnosis, prognosis and monitoring of treatment is of immense public health importance. Since there has not been any known work in molecular profile of tumour markers in women from the target population; this study has provided a ground breaking attempt from where other studies can be conducted.

The prime limitation encountered was that of follow up for the repeat sampling after various forms of treatment because some patients resorted to unorthodox and spiritual healingand some traveled overseas or died. Some patients therefore, were lost to follow-up and that affected the comparison after six months pos-treatment.

\section{References}

[1] Sasco, A.J. (2001) Epidemiology of Breast Cancer: An Environmental Disease? Acta Pathologica Microbiologica Et Immunologica Scandinavica, 109, 321-332. https://doi.org/10.1034/j.1600-0463.2001.090501.x

[2] World Health Organization-WHO (2008) World Cancer Report 2008. International Agency for Research on Cancer (IARC), Natureprint, Lyon Cedex.

[3] Porter, P.L. (2009) Global Trends in Breast Cancer Incidence and Mortality. SaludPublica de Mexico, 51, 141-146. https://doi.org/10.1590/S0036-36342009000800003

[4] Easton, D.F. (2005) Study Shows Women of African Ancestry Diagnosed with More Virulent Form of Breast Cancer. The University of Chicgo Chronicle, 24, 1-3.

[5] Fregene, A. and Newman, L.A. (2005) Breast Cancer in Sub-Saharan Africa. How Does It Relate to Breast Cancer in African-American Women. Cancer, 103, 1540-1550. https://doi.org/10.1002/cncr.20978

[6] Kruger, W.M. and Apffelstaedt, J.P. (2007) Young Breast Cancer Patients in the Developing World: Incidence, Choice of Surgical Treatment and Genetic Factors. South African Family Practice, 49, 18-24. https://doi.org/10.1080/20786204.2007.10873634

[7] Norod, A.A., Brunet, J.F., Ghadirian, A., Robson, M., Heimdal, K., Neuhansen, S.L., Stoppa-Lyonnet, D., Lema, C., Pasini, B., de jos Rios, P., Weber, B., Lynch, H. and 
Hereditary Breast Cancer Clinical Study Group (2000) Tamoxifen and Risk of Contralateral Breast Cancer in BRCA1 and BRCA2 Mutation Carriers: A Case Control Study. Lancet, 356, 1876-1881. https://doi.org/10.1016/S0140-6736(00)03258-X

[8] Kauff, N.D., Satagopan, J.M., Robson, M.E., Schener, L., Hensley, M., Hudis, C.A., Ellis, N.A., Boyd, J., Borgen, P.I., Barakat, R.R., Norton, L., Cartjel, M., Nafak, K. and Offit, K. (2002) Risk Reducing Salpingo-Oophorectomy in Women with BRCA1 and BRCA2 Mutation. New England Journal of Medicine, 346, 1609-1615. https://doi.org/10.1056/NEJMoa020119

[9] Osborn, C., Ostir, G.V., Du, X., Peek, M.K. and Goodwin, J.S. (2005) The Influence of Marital Status on the Stage at Diagnosis, Treatment and Survival of Older Women with Breast Cancer. Breast cancer Research and Treatment, 93, 41-47. https://doi.org/10.1007/s10549-005-3702-4

[10] Celik, S. and Aksoy, G. (2007) Identification of Risk Factors for Breast Cancer for Women in Istanbul. The Open Nursing Journal, 1, 6-12. https://doi.org/10.2174/1874434600701010006

[11] Webster, T.F., Hoffman, K., Weinberg, J., Vieira, V. and Aschengrau, A. (2008) Community- and Individual-Level Socio-Economic Status and Breast Cancer Risk: Multilevel Modeling on Cape Cod, Massachusetts. Environmental Health Perspective, 116, 1125-1129. https://doi.org/10.1289/ehp.10818

[12] Janeway, C.A., Travers, P. and Walport, M. (2001) The Immune System in Health and Disease. Garland Science Publication, New York, 145-153.

[13] Grivennikov, S.I. and Kari, M. (2011) Inflammatory Cytokines in Cancer: TNF and IL-6 Take the Stage. Annals of Rheumatic Diseases, 1, 1104-1108.

[14] Mocellin, S., Wang, E. and Marincola, F.M. (2001) Cytokines and Immune Response in the Tumor Microenvironment. Journal of Immunotherapy, 24, 392-407. https://doi.org/10.1097/00002371-200109000-00002

[15] Suganuma, M., Okabe, S., Kurusu, M., Lida, N., Ohshima, S., Saeki, Y., Kishimoto, T. and Fujiki, H. (2002) Discrete Roles of Cytokines, TNF-Alpha, IL-6, IL-1 in Tumour Promotion and Cell Transformation. International Journal of Oncology, 28, 131-136.

[16] Scott, K.A., Moore, R.J., Amott, C.H., East, N., Thompson, R.G., Scallon, B.J., Shealy, D.J. and Balkwill, F.R. (2003) An Anti-Tumour Necrosis Factor- $\alpha$ Antibodies Inhibits the Development of Experimental Skin Tumour. Molecular Cancer Therapeutics, 2, 445-451.

[17] Zhaorigetu, S., Yanaka, N., Sasaki, M., Watanabe, H. and Kato, N. (2003) Silk Protein, Sericin, Suppresses DMBA-TPA-Induced Skin Tumourigenesis by Reducing Oxidative Stress, Inflammatory Responses and Endogenous Tumour Promoter TNF- $\alpha$. Oncology Reports, 10, 537-543.

[18] Aggarwal, B.B., Shishodia, S., Sandur, S.K., Pandey, M.K. and Sethi, G. (2006) Inflammation and Cancer: How Hot Is the Link? Biochemical Pharmacology, 72, 1605-1621. https://doi.org/10.1016/j.bcp.2006.06.029

[19] Pfeffer, K. (2003) Biological Functions of Tumor Necrosis Factor Cytokines and Their Receptors. Cytokine \& Growth Factor Review, 14, 185-191. https://doi.org/10.1016/S1359-6101(03)00022-4

[20] Moore, R.J., Owen, D.M., Stamp, G., Amott, C., Burke, F., East, N., Holdsworth, H., Turner, L., Rollins, B., Pasparakis, M., Kollias, G. and Balkwill, F. (1999) Mice Deficient in TNF- $\alpha$ Are Resistant to Skin Carcinogenesis. Nature Medicine, 5, 828-831. https://doi.org/10.1038/10552 
[21] Mohamed, M.M., Al-Raawi, D., Sabet, S.F. and El-Shinawi, M. (2014) Inflammatory Breast Cancer: New Factors Contribute to Disease Etiology: A Review. Journal of Advanced Research, 5, 525-536. https://doi.org/10.1016/j.jare.2013.06.004

[22] Englaro, W., Bahadoran, P., Bertolotto, C., Busca, R., Derijard, B., Livolsi, A., Peyron, J.F., Ortonne, J.P. and Ballotti, R. (1999) Tumor Necrosis Factor $\alpha$-Mediated Inhibition of Melanogenesis Is Dependent on Nuclear Factor $\kappa \mathrm{B}$ Activation. Oncogene, 18, 1553-1559. https://doi.org/10.1038/sj.onc.1202446

[23] Stewart, T.H.M. and Heppner, G.H. (1997) Immunological Enhancement of Breast Cancer. Parasitology, 115, S141-S153. https://doi.org/10.1017/S0031182097001832

[24] Guille, A., Chaffanet, M. and Birnbaum, D. (2013) Signaling Pathway Switch in Breast Cancer. Cancer Cell International, 13, 66. https://doi.org/10.1186/1475-2867-13-66

[25] Dinarello, C.A. (1997) Interleukin-1. Cytokine Growth Factor Review, 8, 253-265. https://doi.org/10.1016/S1359-6101(97)00023-3

[26] Dinarello, C.A. (2009) Immunological and Inflammatory Functions of the Interleukin-1 Family. Annual Review of Immunology, 27, 519-550. https://doi.org/10.1146/annurev.immunol.021908.132612

[27] Barksby, H.E., Lea, S.R., Preshaw, P.M. and Taylor, J.J. (2007) The Expanding Family of Interleukin-1 Cytokines and Their Role in Destructive Inflammatory Disorders. Clinical Experimental Immunology, 149, 217-225. https://doi.org/10.1111/j.1365-2249.2007.03441.x

[28] Sheen-Chen, S.M., Chen, W.J., Eng, H.L. and Chou, F.F. (1997) Serum Concentration of Tumor Necrosis Factor in Patients with Breast Cancer. Breast Cancer Research \& Treatment, 43, 211-215. https://doi.org/10.1023/A:1005736712307

[29] Berberoglu, U., Yildirim, E. and Celen, O. (2004) Serum Levels of Tumor Necrosis Factor Alpha Correlate with Response to Neoadjuvant Chemotherapy in Locally Advanced Breast Cancer. International Journal of Biological Markers, 19, 130-134. https://doi.org/10.1177/172460080401900207

[30] Chaloob, F.A. (2014) Estimation of Serum Levels of GM-CSF, IL-1 $\alpha$ and Complement Components C3 and C4 in Patients with Chronic HCV. International Journal of Current Microbiology and Applied Sciences, 3, 695-699.

[31] Jin, L., Yuan, R.Q., Fuchs, A., Yao, Y., Joseph, A., Schwall, R., Schnitt, S.J., Guida, A., Hastings, H.M., Andres, J., Turkel, G., Polverini, P.J., Goldberg, I.D. and Rosen, E.M. (1997) Expression of Interleukin-1 $\beta$ in Human Breast Carcinoma. Cancer, 80, 421-434. https://doi.org/10.1002/(SICI)1097-0142(19970801)80:3<421::AID-CNCR10>3.0.C $\underline{\mathrm{O} ; 2-\mathrm{Z}}$

[32] Richardus, J.M. and Kunst, A.E. (2001) Black-White Differences in Infectious Disease Mortality in the United States. American Journal Public Health, 91, 1251-1253. https://doi.org/10.2105/AJPH.91.8.1251

[33] Hoffman, S.C., Stanley, E.M., Cox, E.D., DiMercurio, B.S., Koziol, D.E. and Harlan, D.M. (2002) Ethnicity Greatly Influences Cytokine Gene Polymorphism Distribution. American Journal of Transplantation, 2, 560-567. https://doi.org/10.1034/j.1600-6143.2002.20611.x

[34] Albert, M.A. (2007) Inflammatory Biomarkers, Race/Ethnicity and Cardiovascular Disease. Nutrition Reviews, 65, S234-S238. https://doi.org/10.1301/nr.2007.dec.S234-S238

[35] Van Dyke, A.L., Cote, M.L., Wenzlaffa, A.S., Land, S. and Schwartz, A.G. (2009) Cytokine SNPs: Comparison of Allele Frequencies by Race and Implications for 
Future Studies. Cytokine, 46, 236-244. https://doi.org/10.1016/j.cyto.2009.02.003

[36] Silver, R.M., Bogatkevich, G., Tourkina, E., Nietert, P.J. and Hoffman, S. (2012) Racial Differences between Blacks and Whites with Systemic Sclerosis. Current Opinions in Rheumatology, 24, 642-648. https://doi.org/10.1097/BOR.0b013e328356d9dc

[37] Pudifin, D.J. and Duursma, J. (1981) Circulating Immune Complexes in Normal Blood Donors of Three Races. South African Medical Journal, 60, 886-887.

[38] Jemal, A., Siegel, R., Ward, E., Hao, Y., Xu, J. and Murray, T. (2008) Cancer Statistics. Clinical Journal of Cancer, 58, 71-96.

[39] Chukwurah, E.F., Uro-Chukwu, H.C. and Uneke, C.J. (2017) Assessment of the Knowledge, Attitude and Practice of Breast Cancer Screening among Female Undergraduate Students of Ebonyi State University. Congress Oral Communication Abstracts: $41^{\text {st }}$ West African College of Physicians Annual Congress, Dakar Senegal.

[40] LaBaer, J. (2013) Autoantibodies in Breast Cancer. Htm Cancer-Biomarkers, Online.

[41] Chukwurah, E.F., Emele, F.E., Iyare, F.E., Nwigwe, C.G. and Ogbodo, S.O. (2016) Evaluation of Circulating Immune Complexes in Patients with Malignant and Pre-Malignant Disease Conditions of the Breast in South-Eastern Nigeria. Journal of Disease and Global Health, 5, 211-217.

[42] Emele, F.E. and Chukwurah, E.F. (2017) Evaluation of Serum Cancer Antigens (CA15-3 and CA27.29) and Circulating Immune Complexes as Important Tools in the Management of Breast Cancer in Nigeria. Journal of Immunology, 198, 76.

[43] Koppolu, P., Durvasula, S., Palaparthy, R., Rao, M., Sagar, V., Reddy, S.K. and Lingam, S. (2013) Estimate of CRP and TNF-Alpha Level before and after Periodontal Therapy in Cardiovascular Disease Patients. Pan African Medical Journal, 15, 92. https://doi.org/10.11604/pamj.2013.15.92.2326

[44] Ben-Baruch, A. (2003) Review: Host Microenviroment in Breast Cancer Development: Inflammatory Cells Cytokines, Chemokines in Breast Cancer Progression: Reciprocal Tumor-Microenviroment Interactions. Breast Cancer Research, 5, 31-36. https://doi.org/10.1186/bcr554

[45] Snouss, K., Strosberg, A.D., Bouaouina, N., Ahmed, S.B. and Chouchane, L. (2005) Genetic Variation in Pro-Inflammatory Cytokines (Interleukin-1 $\beta$, Interleukin-1 $\alpha$ and Interleukin-6) Associated with the Aggressive Forms, Survival, and Relapse Prediction of Breast Carcinoma. European Cytokine Network, 16, 253-260.

[46] Soria, G., Ofri-Shahak, M., Haas, I., Yaal-Hahoshen, N., Leider-Trejo, L., Leibovich-Rivkin, T., Weitzenfeld, P., Meshel, T., Shabtai, E., Gutman, M. and Ben-Baruch, A. (2011) Inflammatory Mediators in Breast Cancer: Coordinated Expression of TNF $\alpha$ and IL- $1 \beta$ with CCL2 and CCL5 and Effects on Epithelial-to-Mesenchymal Transition. BMC Cancer, 11, 130.

https://doi.org/10.1186/1471-2407-11-130

[47] Wang, X. and Lin, Y. (2008) Tumour Necrosis Factor and Cancer, Buddies or Foes? Acta Pharmacologica Sinica, 29, 1275-1288. https://doi.org/10.1111/j.1745-7254.2008.00889.x

[48] Pantschenko, A.G., Pushkar, I., Anderson, K.H., Wang, Y., Miller, L.J., Kurtzman, S.H., Barrows, G. and Kreutzer, D.L. (2003) The Interleukin-1 Family of Cytokines and Receptors in Human Breast Cancer: Implications for Tumor Progression. International Journal of Oncology, 23, 269-284.

[49] Erdemir, G., Ozkan, T.B., Ozgur, T., Budak, F., Kilic, S.S. and Onay, H. (2015) Mannose-Binding Lectin Gene Polymorphism and Chronic Hepatitis B Infection in 
Children. The Saudi Journal of Gastroenterology, 21, 84-89.

https://doi.org/10.4103/1319-3767.153825

[50] Ytting, H., Christensen, I.J., Basse, L., Lykke, J., Thiel, S., Jensenius, J.C. and Nielsen, H.J. (2006) Influence of Major Surgery on the Mannan-Binding Lectin Pathway of Innate Immunity. Clinical and Experimental Immunology, 144, 239-246. https://doi.org/10.1111/j.1365-2249.2006.03068.x

[51] Chen, M.S., Liang, Y., Li, W.F., Wang, M., Hu, L., Abuaku, B.K., Huang, X., Tan, H.Z. and Wen, S.W. (2015) Impact of $M B L$ and $M A S P-2$ Gene Polymorphism and Its Interaction on Susceptibility to Tuberculosis. BMC Infectious Diseases, 15, 151. https://doi.org/10.1186/s12879-015-0879-y 